\title{
His Fate Was Larger than Himself: Andrei D. Sakharov's Centenary
}

\begin{abstract}
IS T V ÁN H A R G IT T A I
Budapest University of Technology and Economics, 1111 Budapest, Múegyetem rkp. 3, Hungary. Email: istvan.hargittai@gmail.com

The world-renowned physicist Andrei D. Sakharov (1921-1989) was 'the father of the Soviet hydrogen bomb' and, as such, an architect of the Soviet superpower. He developed into a fierce fighter for human rights, distinguished by the Nobel Peace Prize. In his words, 'my fate was larger than what would have followed from my personality. I was merely trying to be worthy of my fate.' ${ }^{1}$ His life and career provide thought-provoking lessons and is worthy of review on the eve of his centennial.
\end{abstract}

\section{Under Soviet Reign}

Andrei D. Sakharov (1921-1989; Figures 1 and 2) was born into a Moscow family of intellectuals. His physicist father wrote physics texts and knew Igor Tamm, the future Nobel laureate theoretical physicist. Tamm was an associate of the Lebedev Physical Institute of the Soviet Academy of Sciences (Fizichesky Institut Akademii Nauk, known as FIAN) and later helped Andrei to launch his career. The young Sakharov studied physics at the Lomonosov Moscow State University and, although it was evacuated to Turkmenistan during the Second World War, teaching continued at a high level. After graduation, Sakharov was directed to a plant producing ammunition where he excelled with innovations. He met his future wife at this plant, Klavdia, 'Klava', Vikhireva (1919-1969). She had an incomplete degree in chemical technology and worked in chemical analysis. They married in 1943 and had three children, Tatyana, 'Tanya', in 1945; Lyubov, 'Lyuba', in 1949; and Dmitry, 'Mitya', in 1957. Tanya became a research biologist and Lyuba a librarian (she trained as a physicist). Mitya grew up being fraught with personal problems, worked

1. ‘ . . с судьба моя оказалась крупнее, чем моя личность. Я лишь старался быть на уровне собственной судьбы ...' Андрей Сахаров 1988 г. From a poster at the Moscow Sakharov Archives. 


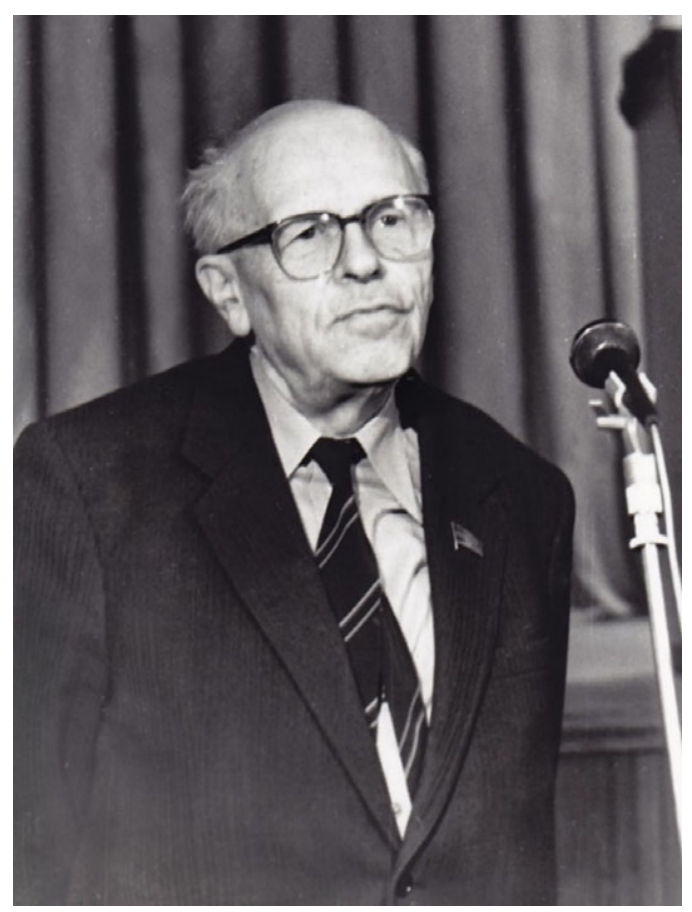

Figure 1. Andrei Sakharov behind the microphone in 1989 (photograph by Anna D. Kudryavtseva, FIAN; courtesy of the Moscow Sakharov Archives).

as a photographer and held entrepreneurial jobs. In 1968, Klava was diagnosed with advanced cancer to which she succumbed the following year. ${ }^{2}$

Following the war, Sakharov landed a position at FIAN. He was lucky to remain untouched by the Stalinist terror raging in full force during the last years of the dictator's life. In previous terrors, outstanding scientists perished - such as the brilliant physicist Lev Shubnikov, the world-renowned biologist Nikolai Vavilov, and many others. The future Nobel laureate theoretical physicist, Lev Landau, was brutally incarcerated. Many scientists and technologists ended up in slave labour camps, such as Sergei Korolev, the future leader of the Soviet space programme (Hargittai 2013).

Sakharov was assigned to be a member of the group of experts, charged with developing the Soviet hydrogen bomb without having been asked whether he wanted to participate in this project or not. He moved, along with Tamm, to Sarov, the closed atomic city, and started work at the secret nuclear laboratory Arzamas-16. By then, the Soviet atom bomb had already been produced as a copy of American design. For the hydrogen bomb, a genuine Soviet contribution was required.

2. She died of stomach cancer. There is no hard evidence, only anecdotal evidence, according to which many wives and daughters of Arzamas scientists died of cancer. Sakharov's family lived in Sarov from 1950 until 1968. Klavdia Vikhireva may have also had chemical poisoning at the ammunition plant where she worked during the war. That poisoning caused stomach ulcers from which she suffered for years. Those stomach ulcers may have also turned cancerous. 


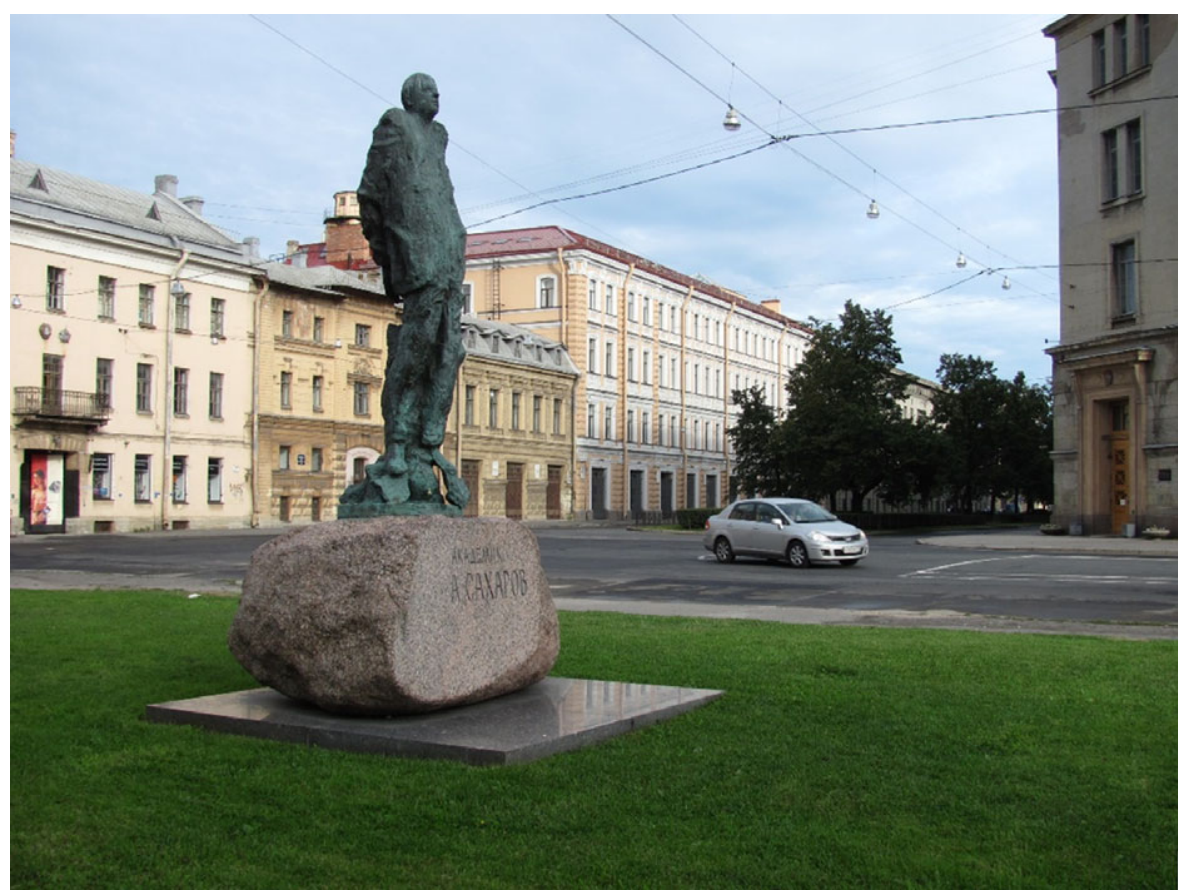

Figure 2. The statue of Andrei Sakharov with his bound hands behind his back (by L.K. Lazarev, unveiled in 2003) on Sakharov's Square in St Petersburg, with the university buildings in the background (photograph by the author).

Sakharov participated in the project with dedication and great success. Three decades later, in the 1980s, at the time of his internal exile, he tried to understand his own unreserved enthusiasm in the 1950s for this horrible project. He did not serve in the Second World War, called the Great Patriotic War in Russia, but in the 1950s he felt like a soldier in a new scientific-technological war. He considered the hydrogen bomb a necessary evil to protect his country against a more powerful enemy than Nazi Germany had been.

Two of the three basic ideas leading to the Soviet hydrogen bomb were Sakharov's; the third was Vitaly Ginzburg's, also a FIAN associate and also a future Nobel laureate. Ginzburg participated in the nuclear project only for a short while as he was not given security clearance. This was on account of his wife, Nina Ermakova, being in internal exile for having, ostensibly, participated in an antiStalin conspiracy long before she met Ginzburg. The accusation was unfounded and her exile ended after Stalin's death (Hargittai and Hargittai 2006).

Prior to moving to Sarov, the secret nuclear installation, the official defence of Sakharov's candidate of science (PhD-equivalent) dissertation took place in 1947 at FIAN. His research was about the theory of transitions in the atomic nuclei. The President of the Academy of Sciences, Sergei Vavilov, presided and two future members of the Academy, Arkady Migdal and Isaac Pomeranchuk, acted as the 
official referees at the defence. Igor Tamm and another luminary of physics, academician Grigory Landsberg, took part in the discussion. Tamm emphasized Sakharov's two traits essential for a theoretical physicist, which rarely occur in the same person. One was the ability to grasp the problem qualitatively and arrive at an approximate estimate of the solution. The other was to solve the problem by exact mathematical tools. The Scientific Council of FIAN voted unanimously to award Sakharov's scientific degree.

According to Sakharov's Memoirs, in spring 1953 the Soviet atom tsar, Igor Kurchatov, initiated Sakharov's election to corresponding member of the Academy. Sakharov was asked to compile the necessary documents for the election anticipated in the fall of the same year. The prerequisite higher doctorate, the DSc degree, was missing, and he acquired it in haste during the hectic work on the development of the hydrogen bomb. This higher doctorate in the Soviet, now Russian, system is also a prerequisite for a professorial appointment. Sakharov did not write a full dissertation, only a summary of his most important results and the defence took place in June at the secret laboratory. Fortunately, it employed more than the sufficient number of qualified scientists to form a Scientific Council for granting his higher doctorate. Igor Tamm was one of the referees whose report was never made public, and is kept in Sakharov's private archive. It does not show a date and does not contain the customary listing of the new scientific results. Yuly Khariton, the scientific director of Arzamas-16, was another referee, and a sanitized version of his report has appeared, dated 9 November 1953, as if it had been compiled after the Academy elections. Khariton mentions Sakharov's achievements in connection with the development of the thermonuclear device.

Sakharov's scientific acumen was amply manifested in 1947 in his candidate of science dissertation and in its defence. He could have been granted the higher doctorate, skipping the candidate's degree, which is not common, but not too extraordinary. His higher doctorate was arranged for during the critical period of the preparation for the test of the experimental thermonuclear device during the summer of 1953. This shows how important his election to the Academy was considered at the time. The first Soviet thermonuclear device - not yet a full-scale hydrogen bomb - was tested on 12 August 1953, with complete success. Sakharov was elected full member rather than corresponding member in the two-tier system of the Soviet Academy of Sciences, on 23 October 1953. In this two-tier system, the corresponding membership precedes the full membership and many corresponding members never reach full membership. Skipping the corresponding membership is most exceptional. Prior examples were Igor Kurchatov in 1943 and Lev Landau in 1946.

A few months following the successful August 1953 test, Sakharov received his first gold star of 'Hero of Socialist Labour'. He was subsequently given this highest recognition twice more, in 1956 and 1962, on both occasions following successful tests of nuclear explosions. He became one of the most decorated Soviet citizens - referred to often as the father of the Soviet hydrogen bomb one of the prime architects of the superpower status of the Soviet Union. 


\section{Personal Transition}

His first collision with the powers that be happened in 1955. Following a successful test - it was the first truly Soviet hydrogen bomb - there was a festive celebration. In his toast, Sakharov expressed his hope that the successful explosions will always happen over proving grounds and never over cities. All those present sensed that the scientist had wandered onto slippery grounds. The representative of Soviet officialdom hastened to correct him with a cautionary tale, to warn the scientist that he should leave politics to the politicians. This was the first time, but not the last, that he was shown his place in Soviet society. When the Soviet Union was preparing to explode the world's most powerful bomb, in June 1961, the supreme Soviet leader, Nikita Khrushchev, conveyed a meeting of the atomic scientists. On this occasion, Sakharov argued that there was no real dividend in deploying bombs of ever-increasing power, whereas their testing carried various dangers. This time, Khrushchev himself reprimanded the scientist and humiliated him publicly in front of the leading scientists and politicians.

Sakharov continued his work at Arzamas-16 for years and was returned to Moscow only in 1968 following his complete alienation from the weapons project. His actions were not determined by his emotions. From the mid-1950s, he was concerned about the possible biological consequences of the nuclear tests. He understood that the biological damages of the tests are non-threshold events; that is, there was no minimum dose beneath which any possible damage could be excluded. The impossible situation of the science of biology in the Soviet Union further enhanced his worries. He was among those physicists and chemists who felt an increasing responsibility to do something to counteract the tragedy of biology and biologists. They were suffering from the iron grip of the charlatan T.D. Lysenko who had enjoyed first Stalin's, then Khrushchev's virtually unlimited support.

On the one hand, Sakharov recognized the biological hazards of testing and felt horrified, witnessing the recklessness of the Soviet leadership in misusing the tests in their international power play. On the other hand, he was concerned to ensure the best possible utilization of the weapons he helped create. At some point he considered the most efficient ways for deploying his horrific invention and approached a Soviet rear admiral, by the name of Fomin, with a proposal. ${ }^{3}$ He suggested equipping a submarine with a hydrogen bomb-torpedo that could be directed to an important Western harbour for maximum destruction. One might dismiss this story as improbable had it not been narrated by Sakharov in his Memoirs (Sakharov 1992, 221). Obviously, with hindsight, this tormented Sakharov. It is just another example of the long road he covered, from the creator of the tools by which Stalin and his successors might have held the democratic world hostage to a most dedicated fighter for democracy.

Sakharov carried out calculations to estimate the possible damage of nuclear tests, including the long-term impacts of the radioactive isotopes they produce. He estimated

3. Sakharov does not give the initials of the rear-admiral but, considering his career, he must be Petr F. Fomin (1904-1976) who commandeered the Soviet atomic submarines when they were first getting deployed. 
that for every megaton (one million ton) TNT-equivalent (2,4,6-trinitrotolueneequivalent) nuclear explosion, there are ten thousand human victims. ${ }^{4}$ By 1957, the nuclear explosions in the world reached 50 megaton TNT-equivalent; the estimated number of human victims reached half a million. It was an ironic quirk of history that Sakharov's estimates, at the time, helped Khrushchev's political interests. The Soviet leader had declared a temporary moratorium on nuclear testing, whereas the Americans continued testing. Sometime later, the Soviets renewed their nuclear testing when Khrushchev's political interests so dictated. Sakharov proved powerless in his attempts to block them.

Sakharov was still an associate of the Arzamas-16 laboratory when he took an activist role during the Academy elections in 1964. He took a stand against the election of an unworthy Lysenko protégé who had secured Party support. As it turned out, other physicists had also formed an opposition and the candidate was not elected. It was an unprecedented action in the history of seamless Party domination in the life of the Science Academy, as in everything else in the Soviet Union. Sakharov was removed from Arzamas-16 in 1968 and returned to FIAN to continue where he began 20 years before. By then, he became actively interested in politics, initially directing his attention to general issues. He signed a protest against Stalin's rehabilitation; joined a movement protesting against the pollution of Lake Baikal in Siberia; and attended a silent demonstration, organized on the Day of the Constitution, to protest against unlawfulness. His participation - he was an academician, three-time Hero of Socialist Labour - added weight to any movement that had him in its midst. The authorities arrested demonstrators and protesters, but never touched him.

\section{For Human Rights}

Gradually, Sakharov's attention moved from general issues to the protection of the human rights of individuals. He attended trials of activists, fought against the use of psychiatric incarceration and for the freedom of religion, against anti-Semitic discrimination, for the right of emigration, and supported numerous other causes, and was on the lookout for more. The Western media helped enhance his fame and he recognized the power of the press.

It was a milestone when, in 1968, he published his pamphlet, smuggled out to the West, Reflections on Progress, Peaceful Coexistence, and Intellectual Freedom. It was a tumultuous year, with the student movements and the Prague Spring and its ruthless suppression, which dissipated any hope for creating 'socialism with a human face'. The world was thirsty for direction and many discovered it in Sakharov's words. He warned the human race of the dangers of 'thermonuclear extinction, ecological catastrophe, famine, uncontrolled population explosion, alienation, and

4. 1 megaton $=1000$ kiloton, and, for comparison, the atom bomb over Hiroshima was 15-kiloton TNT-equivalent. For the number of human victims, Hiroshima could not serve for comparison because an atom bomb targeting a big city directly kills an enormous number of people. 
dogmatic distortion of our conception of reality' (Sakharov 1992, 282). The pamphlet sold at least 18 million copies; only Mao Zedong's and Vladimir Lenin's books preceded it on the bestseller list, and he left behind star authors such as Georges Simenon and Agatha Christie. In many places those in power felt threatened by Sakharov's views, and nowhere as much as in the Soviet Union. The Soviet authorities dreaded the intellectuals and their views; their fear bordered paranoia. They persecuted those who read the pamphlet as well as those who disseminated it. There was a long history of the Soviet authorities considering writers, poets, sociologists, and environmentalists their enemies, even though they possessed nothing except their ideas. Now, a worldrenowned physicist, academician, a principal architect of the Soviet superpower had joined those powerless forces. Although he was a singularity, a lonely hero, he shattered this invincible and eternal - or so it believed - empire.

The widower Sakharov met Elena, 'Lusia', Bonner (1923-2011) in 1970 at a human rights event. She was a divorcee, a paediatrician, war hero, and a human rights activist. They married in 1972. Her children, Tatyana, 'Tanya', and Aleksei became close to him. Bonner was his faithful partner in his heightened human rights activities. When he was awarded the Nobel Peace Prize in 1975, he was prevented from attending the prize-awarding ceremony in Oslo so his wife represented him there. This was because, and it can be taken as symbolic, he was attending a trial of another human rights activist in Vilnius. In subsequent years, Sakharov multiplied his efforts in his fighting for human rights and for freeing incarcerated human rights activists. He did not shrink even from such drastic measures as going on hunger strike.

It says a great deal about the nature of the Soviet regime that among their many attempts to discredit Sakharov they intimated that he may be Jewish and spread stories that might incite anti-Semitic attacks against him - and they did. In his words, these attempts were 'calculated to arouse envy, malice, and all the instincts of the pogrom-makers' (Sakharov 1992, 431). Sakharov followed rigorously Igor Tamm's views on anti-Semitism, according to which there is 'one way of telling if someone belongs to the Russian intelligentsia. A true Russian intelligent is never an anti-Semite. If he's infected with that virus, then he's something else, something terrible and dangerous' (Sakharov 1992, 123; emphasis in original).

Sakharov's dedication and determination rendered the authorities powerless, and in January 1980, they resorted to extreme action to curb his activities. They revoked all his awards and distinctions and, without any legal foundation, exiled him to the city of Gorky - now, as before, Nizhny Novgorod - which was a closed city for foreigners. They did not dare though revoke his membership in the Academy of Sciences.

During the next seven years the authorities kept him, and his wife, who joined him, in isolation. They allowed only once or twice annually one or two of his fellow physicist academicians at FIAN to visit him. An army of KGB agents kept harassing him, stole his manuscripts, scared away his would-be visitors, and did everything to make the Sakharovs' life as hard as possible. Even under these inhuman circumstances Sakharov did not give up taking a stand in defence of others. He was followed every step, spied on all the time, his apartment was tapped, and he was listened to when he talked with others. On one occasion, when he and his rare visitors 
were to discuss some physics that included classified information, he stopped the conversation. He noted that although he and his interlocutors possessed the highest security clearance, the KGB officers listening clandestinely to their exchange might not. Was he being serious or was he sarcastic? Probably both.

\section{The Academy of Sciences in the Background}

Sakharov's inhuman treatment continued during the reign of subsequent supreme leaders, Leonid Brezhnev, Yuri Andropov, Konstantin Chernenko, and Mikhail Gorbachev. Sakharov continued his resistance, including firing off letters of protest to these leaders. Sadly, the Academy of Sciences was among the instruments the authorities enlisted in their efforts to break Sakharov's resolve. It was under Brezhnev, in 1973, that 40 academicians signed a published letter that condemned Sakharov's activities. The signatures were collected unscrupulously. Some of the signatories were not even asked; their names were just added. They could not do this though with everyone. The internationally renowned physicist Petr Kapitsa refused to sign. Yakov Zeldovich, Sakharov's long-time colleague at Arzamas-16, was not even approached. When the president of the Academy, Anatoly Aleksandrov, was called, his wife picked up the receiver and told the caller that her husband was drunk and could not come to the phone, so his signature was also missing. Publishing such letters was a common practice in Soviet times and had become routine. There was a very different letter published in 1983 at the time of Sakharov's exile. This letter was signed by four academicians only, and they did indeed sign it. This letter condemned Sakharov in extreme terms. One of the signatories was the Nobel laureate (1964) laser pioneer Aleksandr Prokhorov and this action left a stain on his brilliant career. It is interesting to note that current Russian officialdom is looking back on Prokhorov's public demeanour with pointed appreciation. Alone among the great generation of Soviet-time physicists, Prokhorov was honoured recently (2015) with a large statue-memorial at one of Moscow's busiest intersections.

As alluded to above, the authorities did not revoke Sakharov's Academy membership, but at one point during his exile he himself raised this issue. By 1984, in the fourth year of his exile, he found his situation hopeless. He was willing to resign from the Academy if the institution proved unable to assist him. This was a drastic proposition, threatening even his livelihood, as the considerable allotment as a full member of the Academy was his principal income at the time. Fortunately, he did not have to resort to this drastic step.

\section{Sakharov and Gorbachev}

The 54-year-old Mikhail Gorbachev ascended to be the new Soviet leader in March 1985. Whether he was set to dismantle the Soviet regime or was being forced to agree to one change after another, has been a question of contention. It is a fact though that during Gorbachev's reign, Sakharov was kept in exile for 18 more long months. 
During this time there were negotiations between Sakharov and the Gorbachev Administration about the terms of his liberation and return to Moscow. Even during these 18 months, Sakharov's harassment continued, and it happened that he had to resort to the extreme action of a hunger strike. Gorbachev was still hesitant about letting Sakharov free when his advisers urged him to do so. In most accounts, Gorbachev 'invited' Sakharov back to Moscow in December 1986, but in reality, and in Sakharov's own words, Gorbachev 'allowed' his return.

Upon Sakharov's return to Moscow he re-joined FIAN, but for the remaining three years of his life politics took over and physics played a diminishing role. His path and Gorbachev's intersected to an ever-increasing degree. Initially, the almighty secretary general, then president, was almost unapproachable for the 'meddlesome' and 'impertinent' intellectual who, rapidly, had become an important player in the Moscow political scene. Sakharov had to be reckoned with unless a politician was ready to ignore the entire intellectual class. At that time this was impossible and unthinkable - today though this is a different matter, as we are observing the diminishing role of this class. Sakharov's statements and criticism are worthy of remembering lest we let the distance in time alter history, belittle Sakharov's role in advancing democratic change, and camouflage Gorbachev's resistance to it.

Sakharov sharply criticized Gorbachev when, in February 1986, the Secretary General declared that there were no longer political prisoners in the Soviet Union and no one was persecuted for political views. This was a false statement as Sakharov himself, still in exile, was direct proof of the opposite. There were still numerous political prisoners. One of their most outstanding representatives, the 48-year-old Anatoly Marchenko died in prison later in 1986. Sakharov protested when Gorbachev's administration initially treated the Chernobyl catastrophe as an insignificant accident, misleading even Sakharov himself. Sakharov later narrated events - by then he was a witness upon his joining the political scene - in which Gorbachev behaved dictatorially at various gatherings and debates, and tended to apply non-democratic approaches, allegedly in order to protect democracy. Sakharov recorded his observations about Gorbachev's tendency to concentrate power in his own hands and observed a deep gap between Gorbachev's words and deeds both in his economic and social policies. He was a political leader who had not yet got used to acquiring political leadership via elections and let his prejudices influence his decisions. Sakharov's uncompromising pro-democracy stand often irritated Gorbachev, who aired his irritation. He was unable to apply his policy of glasnost to his own demeanour and tended to limit openness in his own political activities. Sakharov tried to curb Gorbachev's attempts to grab all power while he also recognized that the new political leader represented a token of progress.

\section{Sakharov's Science}

Sakharov was an internationally renowned physicist whose achievements earned him broad recognition. Alas, he could devote only a fraction of his time to science, and 
even less to basic science. Such a period was the three years at FIAN immediately after the war when he was doing his research in preparation for his candidate of science degree. Some of his work on the thermonuclear bomb he also considered to be true physics. In this, he was not alone. Enrico Fermi did not think it a waste of the time that he spent on developing the nuclear bombs. I am not referring to the importance of the nuclear weapons in preserving peace through mutual deterrence. Rather, much of it was interesting physics (Fermi's expression was good physics), full of challenges for bona fide researchers. During his two decades at the secret atom laboratory, however, Sakharov had hardly any chance to do physics other than what was connected to thermonuclear science. The only opportunity was what came through his fellow physicist Yakov Zeldovich, who was eight years his senior. These eight years of difference meant that Zeldovich had built up a network of connections with other physicists in Moscow prior to the Second World War. This helped him stay alert as far as the rapid progress in physics was taking place in the 1950s and 1960s. His engagement provided stimulus for Sakharov who was rather slow in building interactions with his peers. His 1968 return to Moscow and to FIAN also meant his return to fundamental physics. However, his involvement with human rights issues was gradually taking away an increasing amount of his time from research. Then came the exile, 1980-1986, making it almost impossible to continue doing his physics. It is a manifestation of his extraordinary talent and dedication that during the 1968-1986 period he produced new results and weighty publications that added to his international recognition as a most significant contributor to his science. After his return to Moscow in December 1986, he had hardly any opportunity to continue in physics.

In light of the above, it may seem surprising that his original scientific contributions amounted to a 500-page densely printed volume, published by FIAN (Sakharov 1995). His achievements in the following three areas are especially noteworthy: plasma physics, the physics of elementary particles, and cosmology. Sakharov was the first among Soviet physicists who suggested the application of lasers for controlled thermonuclear reactions. In addition, he was the first to suggest the utilization of neutrons from fusion reactors to produce fission fuels for nuclear reactors. He suggested techniques for the production of extremely strong magnetic fields. Along with fellow Soviet physicists, he initiated the development of tokamak, which is the Russian term for a hot plasma confined to a torus-shape by a powerful magnetic field, which could lead to energy production by the controlled thermonuclear reaction of fusion.

In the physics of elementary particles (today, more often referred to as fundamental particles) he estimated the masses of some of these particles on the basis of the structure of the most fundamental building blocks of matter, the so-called quarks. He communicated his most important, certainly his best known, result involving the interpretation of the so-called baryon asymmetry of the universe. Protons and neutrons are the most common baryons and they constitute much of the known mass of the universe. The baryon-antibaryon asymmetry is part of the fundamental issue of our universe consisting of matter rather than antimatter. 
This issue could be formulated as why does antimatter exist at all? At the moment of the Big Bang, when the universe was formed, it was extremely hot, representing enormous energy, and it produced both particles and antiparticles. As the temperature kept decreasing, the particles and antiparticles annihilated each other in pairs. Had they been present in equal amounts, this would have led to emptying the universe. Apparently, there was some excess of matter over antimatter in the early universe, and this meant the baryon asymmetry and from this followed that the universe now consists of matter. The big question is the origin of the initial imbalance between matter and antimatter, and there has been no solution yet for this puzzle. Sakharov did not provide the solution either, but, in 1967, he set up three requirements that the solution, when it is found, should satisfy. One is that there must exist processes that are capable of altering the number of baryons. The next is the existence of some shift in the natural laws that favours matter over antimatter. And the third is that the processes altering the baryon number must form under the absence of thermal equilibrium - this corresponds to the process of permanent cooling of the universe ever since the initial Big Bang.

The theory of baryon asymmetry links the physics of fundamental particles to cosmology and Sakharov's works played a role in the emergence of the new science of 'CosmoMicroPhysics'. He investigated the problem of the expanding universe, the non-uniform distribution of matter, the reversal of the direction of time, the negative curvature of space, and the finite cosmological constant. Sakharov had a publication on an alternative theory of gravitation and his discussion differed from Albert Einstein's approach, with all the long-ranging consequences of this difference.

\section{Sakharov and Teller}

The authorship of the hydrogen bomb connects the names of these two scientists forever. Edward Teller has been called the father of the American hydrogen bomb and Andrei Sakharov that of the Soviet hydrogen bomb. It is doubtful whether such a label is appreciative or condemning. There is though quite broad consensus that the policy of mutually assured destruction (MAD), however horrible it sounds, restrained the two superpowers for decades from attacking one another. When, in 1985, at the time of Sakharov's exile, an anthology in his honour was published in New York (Andrei Sakharov and Peace), Teller wrote one of its chapters in which he noted that there were similarities between them though he found their differences more significant, hence their stories could not be viewed as running in parallel. (Lozansky 1985). Sakharov and Teller met in person only once, at a banquet honouring Teller on 16 November 1988, in Washington, DC. They had a brief private exchange followed by Sakharov speaking to the gathering. He condemned the Strategic Defence Initiative (SDI), after which he had to leave immediately in order to catch the last plane to Boston. When Teller's turn came to speak, Sakharov was no longer there. Teller expressed his disagreement with Sakharov in the matter of SDI, but did not go into the details of their disagreement, saying 
merely that Sakharov was ill-informed. This was a typical Tellerian approach to debate - Teller should have known that the issue was of principal concern for Sakharov who never addressed any issue without having been thoroughly prepared.

Their differences in opinion manifested themselves most conspicuously in how they viewed the possible biological consequences of nuclear tests. The danger of biological damage was the principal reason why Sakharov opposed further testing. As for Teller, on some occasions he characterized the danger of testing as negligible compared with other sources of possible biological consequences. On other occasions, he emphasized that the unavoidable birth defects as a consequence of testing was an affordable price for enhancing security.

The two men also differed concerning the responsibility of scientists in finding solutions to the most pressing political problems. Sakharov assigned responsibility to scientists and felt uneasy about nuclear destruction and argued for the moral responsibility of scientists in preventing it. Teller emphasized the responsibility of scientists for creating new technical solutions, but shifted the responsibility to Society (or its elected representatives) in their utilization. In this, Teller appeared in concert with the Soviet leadership that was critical toward Sakharov when he appeared to be meddling in nuclear policy. In reality though, Teller was unstoppable in his attempts to influence politicians, to sway their decisions in matters he himself felt strongly about (Hargittai 2010).

Both declared that they did not create their respective hydrogen bombs alone and that it was the work of many people. Sakharov's assessment was realistic when he mentioned Vitaly Ginzburg's suggestion as one of the three fundamental ideas in developing the Soviet bomb, along with the participation of Yakov Zeldovich and others. In contrast, Teller belittled Stanislaw Ulam's contribution, which may have triggered Teller's approach that moved the project to completion.

Both had excellent ability to make qualitative estimates when facing a problem and arriving at a qualitative solution; only then did they elaborate the details. Both reconciled fundamental research and applications; in fact, both devoted themselves to seeking applications of the fruits of basic research. Both were dedicated to the utilization of nuclear science for energy production. Teller in his time played a leading role in creating safe operational protocols of nuclear power plants in the United States. This needs emphasis as this aspect of his career is hardly known. Both advocated the importance of operating nuclear power plants underground. It is now over 30 years that both declared this mandatory for new nuclear reactors and their strong recommendations appear to have been unheeded.

They were different in their public appearances. Sakharov had a withdrawing personality; he did not like impromptu interviews; he was not a practised debater. Teller, however, thrived on public appearances, enjoyed live interviews and, when it was a recording, he insisted that it should not be edited; rather, the transcripts should appear unaltered or not at all. He was an excellent debater; most of his interlocutors thought him invincible in debate. Sadly though, he did not always operate with fairness, and liked to intimate knowledge that was in his favour but that he was not at liberty to divulge. 


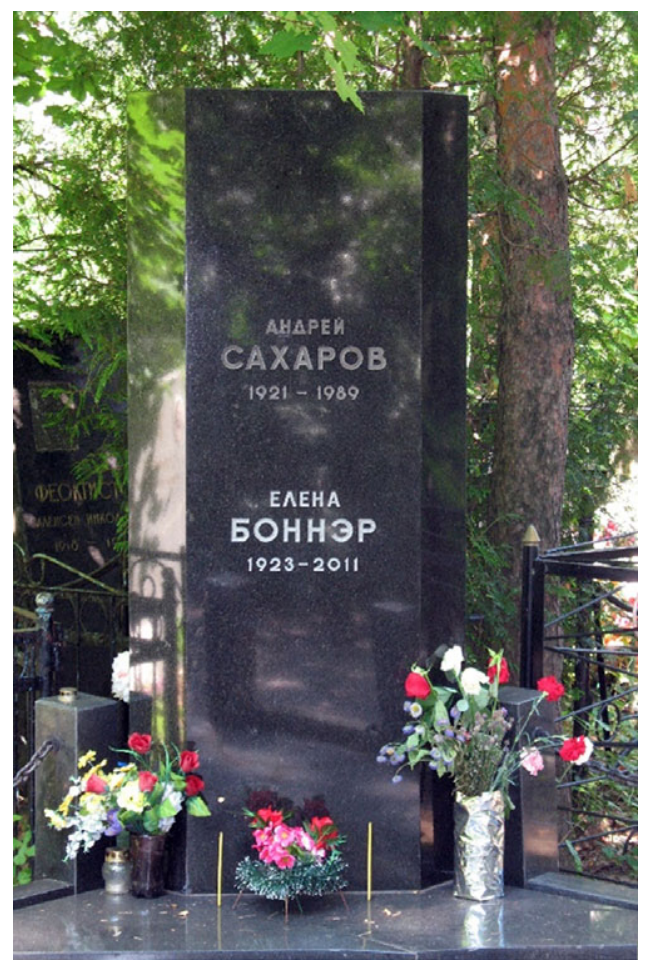

Figure 3. Sakharov's grave in the Vostryakovskoe Cemetery in Moscow (courtesy of Aleksandr Verny). Sakharov's second wife, Elena Bonner, is buried in the same grave.

Sakharov respected Teller and his principal arguments regardless of whether he agreed with him or not. A critical comparison of the careers and views of the two should be instructive. Whether they ran in parallel, though, is questionable. To me, considering the directions of their careers and views, they followed, rather, anti-parallel paths.

\section{Demise}

Sakharov died in 1989 just as the Soviet Union was dissolving. His status and his contributions to his country having become a superpower, as the 'father of the Soviet hydrogen bomb', would have made him eligible for a most prestigious burial place. He might have been buried in the Kremlin Wall, as Mstislav Keldysh and Sergei Korolev of the space programme were. He certainly could have been buried in the most exclusive Novodeviche Cemetery, as Igor Tamm, Yakov Zeldovich, and Vitaly Ginzburg of the nuclear weapons programme were (Hargittai and Hargittai, 2019). When Sakharov's first wife died, he arranged for her burial at the Vostryakovskoe Cemetery, anticipating that, when the time came, he would also be buried there. Indeed, his final resting place is there, together with his second wife, not far from that of his first wife (Figure 3). 


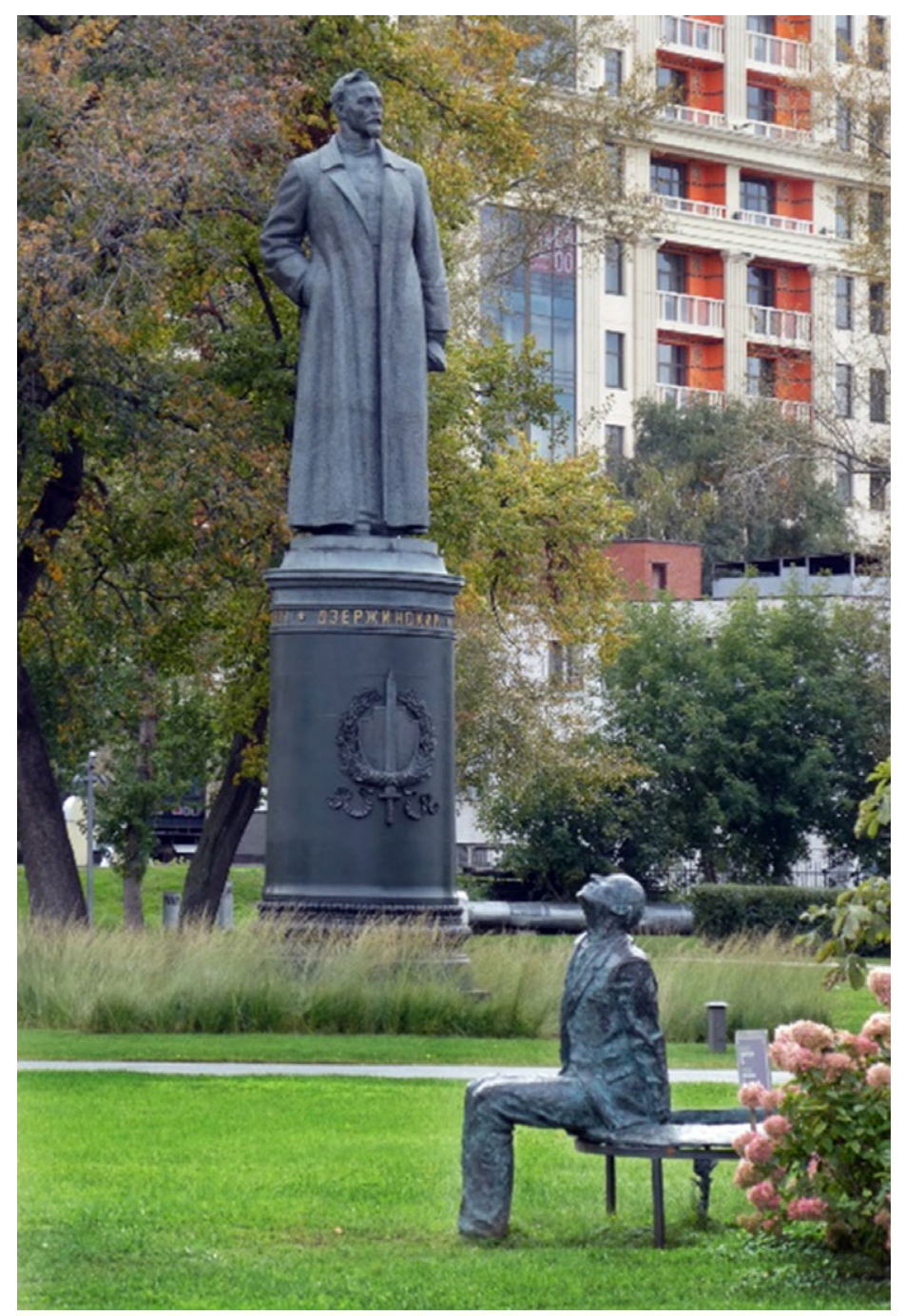

Figure 4. Statues of Feliks Dzerzhinsky (left, by E.V. Vuchetich, 1958) and Andrei Sakharov (right, by G.V. Pototsky, 2008) in the Muzeon Park, Moscow (photograph by the author).

\section{Epilogue}

The Muzeon Park is a beautiful and popular centre of art and entertainment close to downtown Moscow and it includes a huge collection of statues. It began right after the collapse of the Soviet Union and the intention was to collect the memorials of the discredited regime. After a while though, the direction of the sculpture park changed. Many of the memorials that should have become part of the collection were left in their original locations, whereas many other statues that had nothing to do with the Soviets were exhibited at the Muzeon Park. This is how the statues of Feliks 
Dzerzhinsky and Andrei Sakharov happen to stand now in each other's vicinity (Figure 4). Dzerzhinsky founded the predecessor of the infamous KGB in the 1920s and his monumental statue used to be a landmark on Lubyanka Square in front of the KGB (today, FSB) Headquarters. Sakharov's statue was created in 2008 and were it not labelled properly it could be taken merely for an old man sunbathing peacefully. In juxtaposition, the two statues form a symbolic ensemble; there is Sakharov as David, and Dzerzhinsky as Goliath. David/Sakharov for years fought for human rights, which for a long time was thought to be hopeless, against an invincible regime represented here by Goliath/Dzerzhinsky. Then, finally, this frail man defeated the mighty order, which collapsed like a house of cards. Following his death, the respect for and reputation of Sakharov grew enormously. It appeared as if the process of democratization in Russia, symbolized by Sakharov, won - using a favourite expression of Soviet times - a complete and final victory over the forces symbolized by Dzerzhinsky. Alas, the development in Russia during the past years and decades demonstrates that Sakharov's victory may have not been complete, nor final (this is as of Fall 2020). There may be need for new Sakharovs!

\section{Acknowledgements}

I thank Aleksandr Verny, Sakharov's son-in-law, for information about Sakharov's higher doctorate, and Marina Sakharov-Liberman, Sakharov's granddaughter, for information about Sakharov's first wife and their children.

\section{References}

Hargittai I (2010) Judging Edward Teller: A closer look at one of the most influential scientists of the twentieth century. Amherst, New York: Prometheus Books.

Hargittai I (2013) Buried Glory: Portraits of Soviet Scientists. Chapter 3, Andrei Sakharov: Soviet Conscience. New York: Oxford University Press, pp 58-91.

Hargittai I and Hargittai M (2006) Candid Science VI: More Conversations with Famous Scientists. Chapter 40, Vitaly L. Ginzburg. London: Imperial College Press, pp 808-837.

Hargittai I and Hargittai M (2019) Science in Moscow: Memorials of a Research Empire. Singapore: World Scientific.

Lozansky ED (ed.) (1985) Andrei Sakharov and Peace. New York: Avon Books, pp. 107-118.

Sakharov AD (1992) Memoirs (Translated from the Russian by Lourie R). New York: Vintage Books.

Sakharov AD [Сахаров АД] (1995) Научные труды. Москва: ЦЕНТРКОМ. 


\section{About the Author}

István Hargittai is Professor Emeritus (active) at the Budapest University of Technology and Economics. He is a member of the Hungarian Academy of Sciences and the Academia Europaea (London) and a foreign member of the Norwegian Academy of Science and letters. Among his distinctions are honorary doctorates of Lomonosov Moscow State University and of the Russian Academy of Sciences. He is the author of Buried Glory: Portraits of Soviet Scientists (2013) and co-author, with Magdolna Hargittai, of Science in Moscow (2019). His most recent book is Mosaic of a Scientific Life (2020). 